\title{
Development and Validation of Perceived Stigmatization in Sports Scale for Female
} Athletes

\author{
Sahar Saleem ${ }^{1}$, Vicar Solomon ${ }^{2}$, Farah Malik ${ }^{3}$
}

\begin{abstract}
The current study aimed to develop an indigenous, valid and reliable perceived stigmatization in sports scale for female athletes (PSSSFA). Eight in-depth, detailed and semi-structured interviews were conducted with female athletes, whereas, the preliminary item pool of twenty items was administered on 125 female university athletes. The age was $18-24$ years $(M=21, S D=1.6)$. The process of scale development depended upon two phases. The first phase was about construct conceptualization through interviews and the second phase consisted of examining factor structure and reliability of the scale. Perceived Stigmatization in Sports Scale for Female Athletes was developed in Urdu. Total 20 items were developed but the final scale included 18 items with fivepoint rating scale. On the basis of scree plot and Eigen values, three factors were extracted: Family Stigmatization included 6 items and had .82 reliability, Social Stigmatization included 5 items and had .75 reliability and Effect on Performance included 7 items and had .76 reliability. The overall Cronbach alpha value was .88. The findings of the study tended to investigate factors affecting the perceived stigmatization associated with female athletes and these results would help in providing awareness regarding challenges being faced by female athletes in their respective sports.
\end{abstract}

Key Words: Perceived Stigmatization, Female Athletes, Sports

Received: 03 December 2021; Revised Received: 21 December 2021; Accepted: 25 December 2021

${ }^{1}$ BS (Hons) Scholar, Institute of Applied Psychology, University of the Punjab, Lahore, Pakistan.

${ }^{2}$ Assistant Professor, Department of Psychology, University of Jhang, Pakistan. ${ }^{3}$ Professor, Institute of Applied Psychology, University of the Punjab, Lahore, Pakistan.

\section{Corresponding Author Email:}

vicarsolomon5@gmail.com

\section{Introduction}

The issues of female athletes have been remained a topic of interest for researchers from long time. The way number of females increasing with time in the sports field making this topic to get more attention in the literary world. Apparently, physical movement and sports activities bring many health benefits to every individual even in all ages but still some prominent issues are the factual realities of female athlete's life. We are living in the patriarchal world where strength and rigorous physical movements are always considered as man's characteristics. Though, women on the other hand, considered as fragile and not made for hard physical activities. They got attention more about their physical appearances rather than their sports abilities (Frost et al., 2011). Due to this societal mind-set, females are hard to find their due place in the athletic field until they truly achieve something big. However, whenever a female tends to go against this conventional schema of the society, many hazards come along in her way. The issues like societal mind-set, lack of conventional girlish lifestyle and hormonal imbalance are the concerned challenges for female athletes (Jones, 2002). Additionally, talking about the field, low funds for tournaments, less winning amounts and reduced broadcast time for their matches as

This article is distributed under the terms of the Creative Commons Attribution Non Commercial 4.0 License (http://www.creativecommons.org/licenses/by-nc/4.0/) which permits nonCommercial use, reproduction and distribution of the work without further permission provided the original work is attributed as specified. 
compared to men are also some of main concerns of female athletes. Even though female competitors are breaking the stereotypes and exploring new horizons, still they are typified. So, these were some issues faced by female athletes which should need to get addressed on national level (Slade \& Owens, 2009).

At first, we scrutinize how the prevailing definitions of stigma have been depicted. Having said that, we'll also look upon how the social elements of stigma have been conceived. Stigma was defined by Brown et al. (2004) as deeply discrediting attribute. Furthermore, he suggested that it's a phenomenon in which a person or group of people was deliberately targeted as unusual part of community. Additionally, he mentioned stigma as part of a huge social development system and as a link between stereotype and particular attribute of targeted people. The term mark was used by Link et al. (2014) which was emphasized by the past view of stigma as an attribute, to portray a degenerated condition recognized by society that may characterize the person as defective or ruined. In spite of the fact that Link et al. (2014) portrayed the stigmatizing procedure as social i.e., the social condition characterizes what exactly is freak and gives the setting in which degrading assessments are communicated.

As a characteristic of the individual, other social mental plans have additionally found. Within a social context, researchers like Ames (2012) explained the construct of stigma as when an individual portray what is accepted as a "frequently objective" characteristic or highlight that passes on a degraded social personality. This personality is then socially built by characterizing who has a place with a specific social gathering and whether a trademark will prompt a debased social character in a given setting. Likewise, Alvarez et al. (2012) also proposed it as a social identity which is devaluing.
Thus, stigma is characterized as comprising of a character to stamp individuals at various levels which prompts devaluation; and is reliant both on relationship and setting that stigma is socially developed (Mallinson et al. 2017). In view of developmental brain science, a viewpoint in conjunction with the experiences, these conceptualizations catch numerous essential parts of stigma. As a wide umbrella idea that connects interrelated disgrace segments proposed a meaning of human science of shame. The initial four segments of their definition marking, stereotyping, subjective partition, and passionate responses included Alvarez et al (2012) distinguished social procedures that happen inside the sociocultural condition whose impacts can be seen inside the person as indicated by the social mental definitions. Status loss and discrimination being the fifth segment of Link and Phelan's definition incorporates auxiliary segregation. Likewise, novel to the conceptualizations considered is Link and Phelan's thought that the disgrace procedure relies upon the utilization of social, financial, and political power that pervades the previous shame segments with biased outcomes (Crocker et al., 2008).

In the previous couple of decades, ladies have made enormous advances, in terms of investment and correspondence. In all fields of life, it is possible that it is workforce or legislative issues in this day and age it is extremely basic to see the female's cooperation. In numerous societies, however, it is for the most part acknowledged that ladies can share in features of life that were once viewed as male-situated, there are as yet numerous marks of disgrace that encompass females that did as such (Frost \& Marten, 2011). This is particularly evident in the territory of games. Generalizations and traditions related with biased parts, they are thought to be atypical point when individual disregard. As the two understudies and competitors Student-competitors must 
manage the part strife natural in going according to the definition. Gender part must be adjusted by the female competitors. Female competitors illustrate a higher measure of a part struggle than male competitors found by the Mageau \& Vallerand (2003) in addition to the contention. The contention was observed to be predominant for female competitors taking an interest in generally manly games, for example, baseball, football, soccer, hockey and basketball.

For some female competitors, participation in sports that require what are considered normally "male qualities, for example, speed and quality can show a "picture issue". While some exploration presents self-view of female competitors partaking in cross-sexual orientation dons the impression of others may not be as positive (Vazou et al., 2005). Regarding the treatment of female competitors, the negative response of others can bring about unfavourable outcomes. The confusing connection amongst manly and female practices is additionally predominant in regular daily existence which was proposed by Jowett and Poczwardowski (2007). To adjust to the perfect female image which is regularly characterized by society and culture as being little sleek and demonstrated that the thing that female competitors frequently endeavour. Then again, in an athletic setting, female competitors express little want to adjust to the ladylike perfect and are regularly pleased with their muscles, quality, and "manly" highlights. Female competitors detailed experiencing difficulty discovering garments that fits their strong bodies and regularly eat a bigger sum than their non-competitor female companions (Crocker et al., 2008).

As good examples, female competitors' womanliness, sexual introduction, and suitability are what inquiries are regularly raised with respect to female competitors. Female competitors frequently endure a lot of part struggle in different parts of their lives, including at school, work, and get-togethers which may prompt the experience of elevated amounts of pressure just because of gender orientation part infringement (Link \& Phelan, 2001). To evade the picture issue by underscoring female competitors' hetero connections in the news as opposed to focusing on their athletic accomplishments by the media is confirmed. Part strife is additionally exacerbated by the endeavour of numerous female competitors to overcompensate for their manly conduct on the field by acting in ladylike courses off the field. Standards for the "female games world" and whatever is left of society vary significantly (Vazou et al, 2005).

Considering the gender related experiences, these experiences of female athletes were attributed in three-fold. Being in the field, they need to manage their athletic identity and specially, they get to balance the athletic expectations and societal norms. Moreover, they were expected to separately address both their female and athletic characteristics hand in hand before entering the field (Smith et al., 1995). So, coming to the three-fold genderbased approaches in the sports field for female athletes, confronting the invisible gender related issues, tackling the routinebased gender issues and try to reduce the gender-based politics and gender differences. Overall, it is quite difficult to handle all of them because every female athlete comes from different social class, race and hold different personality traits. That's why the researcher in the present study tended to address their subjective experiences being in the sports field. Sexual orientation generalizations in sports persevere likewise featured by the Brown et al. (2004). The creators investigated the degree to which ladies' intercollegiate competitors relate to and characterize sexual orientation issues amid their examination. Study members made three particular distinguishing pieces of 
proof that their status in games is auxiliary to that of men, that ladies' game doesn't generally make a difference, and that societal impression of ladies competitors were stereotyped as being lesbian, butch, spitfire, or manly. Ladies' investment and involvement in sports are affected by sexual orientation generalizations demonstrated by these discoveries (Ames, 2012).

In a nutshell, as literature has reported that all these variables are studied separately but not studied together. However, the study variables are still comparatively less explored so the purpose of this research is to explore the effects of perceived stigmatization on female athletes. Female athletes are less likely to accept in our society and are somehow criticized by the society and family (Stoeber \& Otto, 2006). This study highlighted the negative influences of perceived stigmatization on athlete's perfectionism and performance and also benefited the society by emphasizing the positive influences of motivational climate on athlete's perfectionism and performance. Moreover, it would help to empower the women and to help the female athletes to cope with their societal and other issues as well (Smith et al, 1995).

\section{Method}

The development and validation of the perceived stigmatization in sports scale for female athletes (PSSSFA) was carried out in two phases. Phase I incorporated construction and validation after generating initial item pool by conducting interviews of female university athletes; however, Phase II encompassed determining psychometric properties of the newly developed scale.

\section{Phase 1}

Construction and Validation of Perceived Stigmatization in Sports Scale for Female Athletes (PSSSFA)

Phase I was carried out to construct and validate an indigenous scale, perceived stigmatization in sports scale for female athletes (PSSSFA). In-depth, semi-structured and detailed interviews were conducted with eight female university athletes $(n=8)$ who were admitted in different departments on sports quota having age between 18-24 years $(M=21, S D=1.6)$. Perceived Stigmatization in Sports Scale for Female Athletes was developed in Urdu, the national language of Pakistan.

\section{Conception of the Construct}

Firstly, the conception of the construct was done by enriched study of literature published in the field of sports psychology across globe especially related to female athletes and their problems. After that, it was important to select items that suitably and accordingly emulate stigmatization that the female athletes face. For this purpose, eight interviews were conducted.

\section{Interview Questions}

In depth interviews were conducted with female athletes of university. The previous literature helped to prepare the interview guide. Interviews were conducted with eight university female athletes individually. The interviews were started with the instructions and aim of the study. It was guaranteed to the participants that their data would be kept between ourselves and would not be used for other purposes. The participants were instructed to share their true experiences regarding perceived stigmatization faced by them. Interviews were conducted in Punjab University and were tape recorded. Each interview lasted for half an hour. Later, the transcription of the interviews was done. Following were the interview questions: 


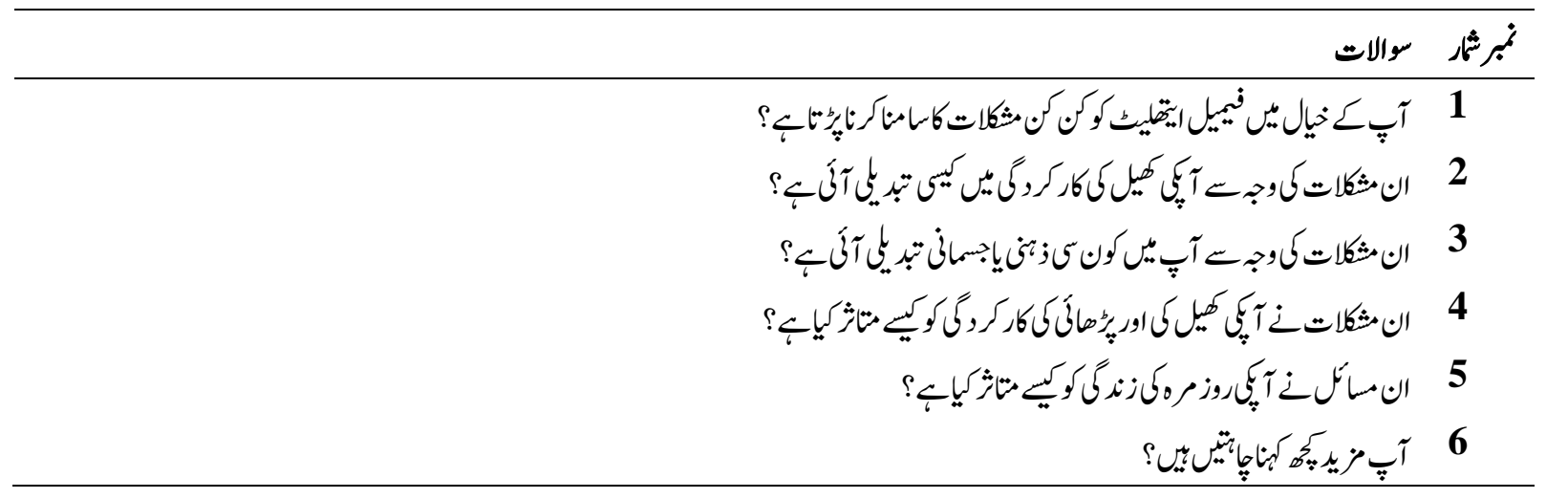

Generation of Item Pool for Perceived Stigmatization in Sports Scale for Female Athletes (PSSSFA)

Eight in-depth, detailed and semi-structured interviews were audiotaped and then transcribed. Items were generated from the transcribed content directly so that the original meaning of the construct may not be disregarded. For the collaboration of the format of the responses and for eradication of the overlapping, redundant items, and assure the validity regarding face and content, committee approach was used. The committee included five skilled ( 3 men and 2 women) professionals including MPhil degree holders $(n=3)$, $\mathrm{PhD}$ scholars $(n=1)$ and $\mathrm{PhD}$ degree holder $(n=1)$. All the penal members were competent and have expertise in test construction. Those items were discarded which were unimportant and overlapping. The judges

\section{Table 1}

Demographic Characteristics of Sample (N=125)

\begin{tabular}{lcc}
\hline Variables & $\boldsymbol{F}$ & $\mathbf{\%}$ \\
\hline Age & & \\
18-20 years & 49 & 39.2 \\
21-24 years & 76 & 60.8 \\
Education & & \\
$\quad$ BS & 80 & 64 \\
$\quad$ MSc & 45 & 36 \\
\hline Level
\end{tabular}

Note: $F=$ frequency, $\%=$ percentage

Factor Structure and Reliability Analysis

Factor analysis and reliability analysis were run in the phase II of scale development. For suggested the changed in the statements of the items. Therefore, the number of items was sloped from 20 to 18. The penal members passed 5-point Likert type response pattern for the scale.

\section{Phase 2}

\section{Psychometric Properties of PSSSFA}

In phase II Exploratory Factor Analysis was used to determine factorial structure and to carry out reliability analysis.

\section{Sampling Strategy and Sample}

The sample comprised of 125 female university athletes between the age range of 18 -24 years $(M=21, S D=1.6)$ recruited via purposive sampling technique. The sample was drawn from different universities with minimum 12 years of education. Only university athletes were taken. The detailed demographic information of the participants for factor analysis is shown in Table 1:

\begin{tabular}{lll}
\hline University & 90 & 72 \\
National & 35 & 28 \\
Residence & & \\
Hostel & 72 & 57.6 \\
Day Scholar & 53 & 42.4 \\
Nature of Game & & \\
Individual sports & 45 & 36 \\
Team sports & 80 & 64 \\
\hline
\end{tabular}

the factor structure of the items of final scale, factor analysis was conducted and for alpha internal consistency, reliability analysis was 
done. For this purpose, Principal Component Analysis, followed by Oblique Rotation on 125 responses of the participants on 20 items was carried out. Oblique Rotation was used to perform Principal Component Analysis because the data was found to be oblique and had inter-item correlation (Table 2). Bartlett's test of sphericity was observed highly significant, sphericity was observed highly significant, $\chi^{2}(8385)=881.03, p<$ .001 which indicated correlations between items were sufficiently large for PCA (Hutcheson \& Sofroniou, 1999). So, the choice was to use scree plot. Eigen values for factor I, II and III were appropriate.

Table 2

Kaiser-Myer Test for Sampling Adequacy and Bartlett's Test of Sphericity (N=125)

\begin{tabular}{ll}
\hline Kaiser-Myer-Olkin Test for Sampling Adequacy & .81 \\
Bartlett's test of sphericity, Approx. $\chi^{2}$ & $881.03^{*}$ \\
$d f$ & 190 \\
$*_{p}^{*}<.001$. &
\end{tabular}

To determine how many components (factors) to 'extract', there was a need to consider a few pieces of information provided in the output. Using Tabachnick and
Fidell (2007) criterion, the interest was only in components that have an eigen value of 1 or more.

\section{Figure 1}

Scree plot showing the Extraction of Factors for Perceived Stigmatization in Sports Scale for Female Athletes (PSSSFA)

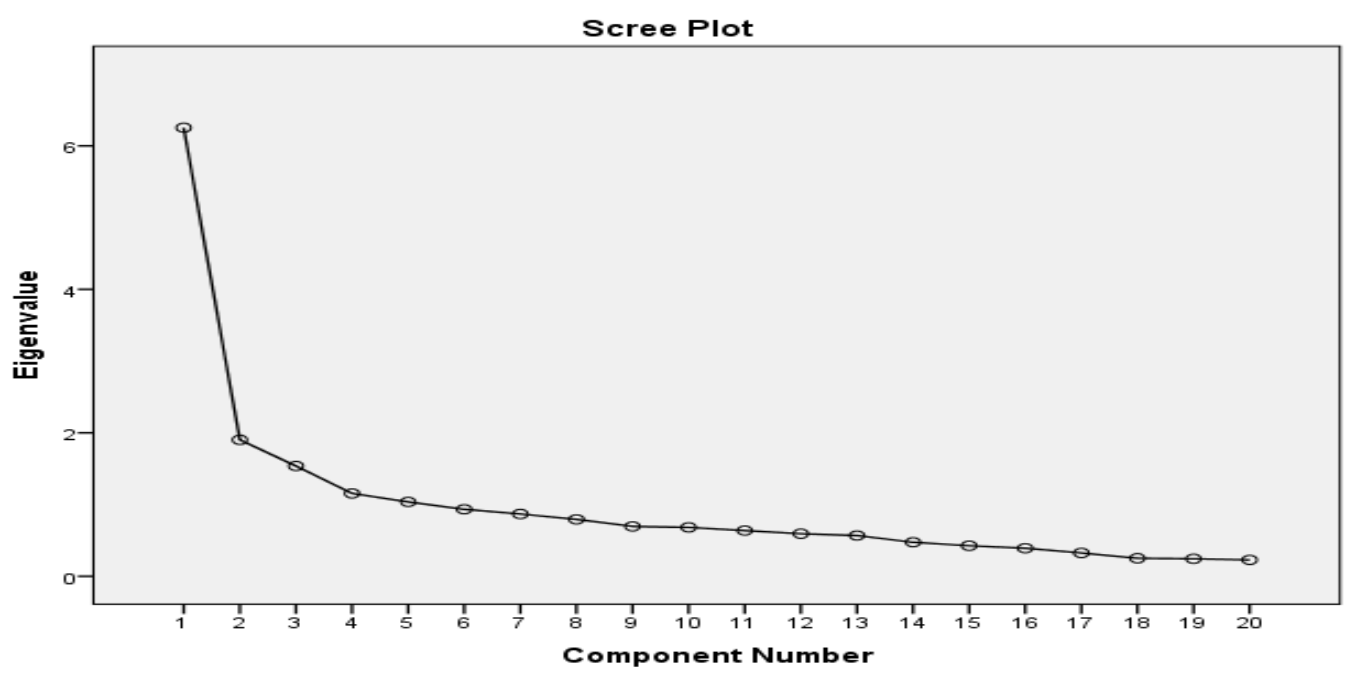

Cattell's scree plot (1966) criterion calls for retaining those factors that lie above point of inflation of the plot. The scree plot (Figure 1) suggested three factors solutions.

The figure of the scree plot showed that 3 factors were extracted, therefore Principal Component Analysis was carried out with three factors. The criteria of having factor loadings of 0.35 and above was used for the selection of the items of the subscale (Harrell, 2000). The Table 3 represent the factor loadings of 20 items of the PSSSFA on three factors using Oblimin Rotation. 


\section{Scoring and Interpretation}

There were 20 items in the initial item pool and for measuring the frequency of the responses, 5-point likert scale was used $(1=$ Totally Disagree, $2=$ Disagree, $3=$ neither Agree nor Disagree, 4= Agree, 5=Totally Agree). Total score on the scale ranges from 5 (minimum) to 100 (maximum). The final Scale included 18 items with five-point rating scale. The Cronbach alpha value was .88 indicating appropriate reliability. The Perceived Stigmatization in Sports Scale for Female Athletes has three subscales. The scoring and interpretation of these subscales are as follows:

\section{Factor 1: Family Stigmatization}

The factor 1 is Family Stigmatization including 6 items with .82 reliability. The score range on this scale is from 6 (minimum) to 30 (maximum).

\section{Factor 2: Social Stigmatization}

The factor 2 is Social Stigmatization that included 5 items and has reliability .75 . The score range on this scale is from 5 (minimum) to 25 (maximum).

\section{Factor 3: Effect on Performance}

The factor 3 is Effect on Performance. It included 7 items and has reliability .76. The score range on this scale is from 7 (minimum) to 35 (maximum).

\section{Table 3}

Factor Loadings for Exploratory Factor Analysis with Oblimin Rotation of Perceived Stigmatization in Sports Scale for Female Athletes (PSSSFA)

\begin{tabular}{|c|c|c|c|c|c|}
\hline \multirow[b]{2}{*}{$\begin{array}{l}\text { Sr. } \\
\text { No. }\end{array}$} & \multirow[b]{2}{*}{ Statements } & \multicolumn{3}{|c|}{ Factor Loadings } & \multirow{2}{*}{$r^{i t}$} \\
\hline & & 1 & 2 & 3 & \\
\hline 1 & 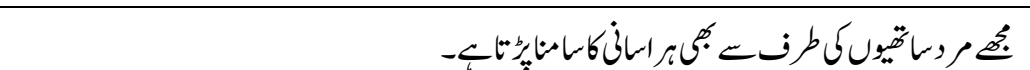 & .59 & & & .20 \\
\hline 2 & 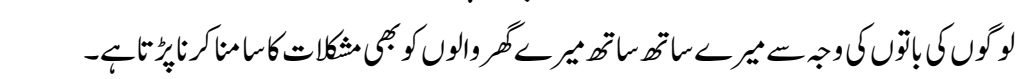 & .57 & & & .22 \\
\hline 3 & 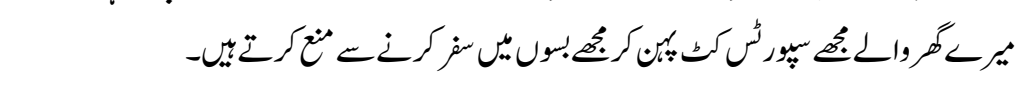 & .64 & & & .32 \\
\hline 4 & 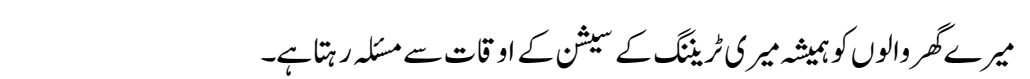 & .72 & & & .20 \\
\hline 5 & 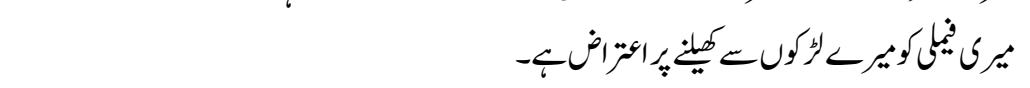 & .59 & & & .14 \\
\hline 6 & 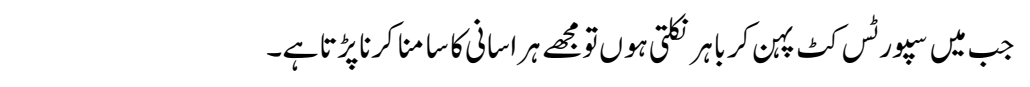 & .77 & & & .30 \\
\hline 7 & 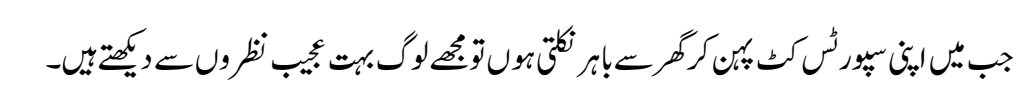 & & .44 & & .32 \\
\hline 8 & 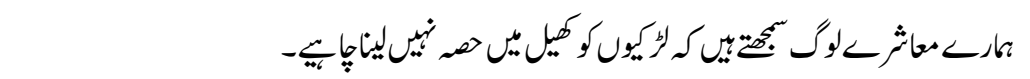 & & .73 & & .20 \\
\hline 9 & 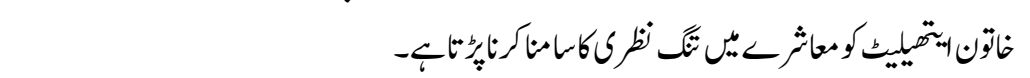 & & .64 & & .30 \\
\hline 10 & 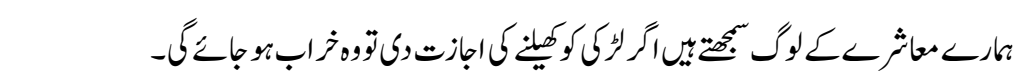 & & .69 & & .30 \\
\hline 11 & 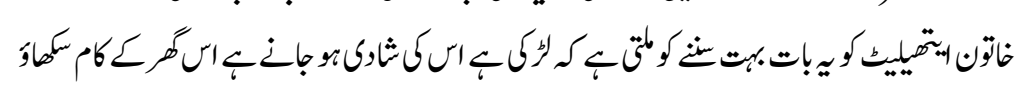 & & .75 & & .30 \\
\hline & 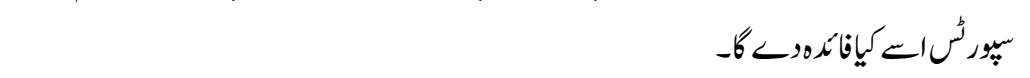 & & & & \\
\hline 12 & 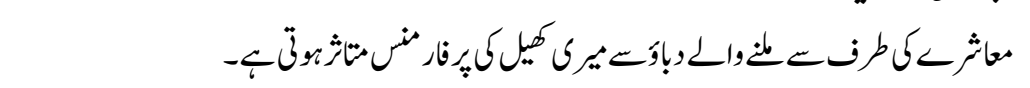 & & & .53 & .24 \\
\hline 13 & 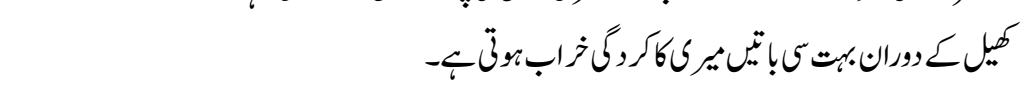 & & & .55 & .20 \\
\hline 14 & 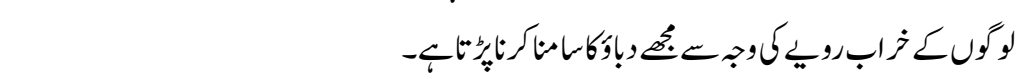 & & & .45 & .30 \\
\hline
\end{tabular}




\begin{tabular}{|c|c|c|c|c|c|}
\hline 15 & 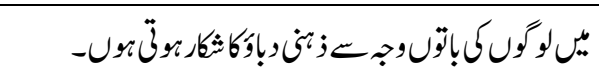 & & & .75 & .42 \\
\hline 16 & 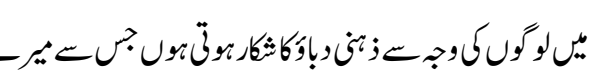 & & & .70 & .11 \\
\hline 17 & 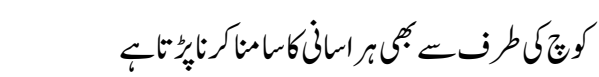 & & & .58 & .19 \\
\hline \multirow[t]{5}{*}{18} & 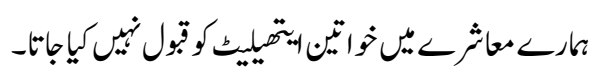 & & & .45 & .21 \\
\hline & Eigen Value & 6.25 & 1.90 & 1.53 & - \\
\hline & $\%$ of Variance & 31.26 & 9.51 & 7.68 & - \\
\hline & Cumulative $\%$ of Variance & 31.26 & 40.77 & 48.46 & - \\
\hline & Cronbach's Alpha & .82 & .75 & .76 & - \\
\hline
\end{tabular}

Note: Factor Loadings $\geq .40, r^{i t}=$ item total correlation

\section{Table 4}

Correlation of the Perceived Stigmatization in Sports Scale for Female Athletes (PSSSFA)

\begin{tabular}{llll}
\hline Variables & Family Stigmatization & Social Stigmatization & Effect on Performance \\
\hline Family Stigmatization & - & $.47^{* *}$ & $.55^{* *}$ \\
Social Stigmatization & - & - & $.42^{* *}$ \\
Effect on Performance & - & - & - \\
\hline
\end{tabular}

The results in Table 2 indicates that all three factors (family stigmatization, social stigmatization and effect on performance) have significant positive relationships with each other and also with total score of PSSSFA.

\section{Table 5}

Descriptive of the Perceived Stigmatization in Sports Scale for Female Athletes (PSSSFA)

\begin{tabular}{llll}
\hline Factors & $\boldsymbol{M}$ & $\boldsymbol{S D}$ & $\boldsymbol{\alpha}$ \\
\hline Family Stigmatization & 18.31 & 5.29 & .82 \\
Social Stigmatization & 18.08 & 3.89 & .75 \\
Effect on Performance & 22.66 & 4.83 & .76 \\
Perceived Stigmatization in Sports Scale for Female Athletes & 65.44 & 12.49 & .88 \\
(PSSSFA) & & & \\
\hline
\end{tabular}

Mean, quartiles, standard deviation, and reliability coefficient of Perceived Stigmatization in Sports Scale for Female Athletes (PSSSFA) was shown in the Table

\section{Discussion}

Perceived Stigmatization in Sports Scale for Female Athletes yielded three sub-scales as family stigmatization, social stigmatization and effect on performance. At first, we scrutinize how the prevailing definitions of stigma have been depicted. Duda and Balaguer (2007) described that a special kind
5. Cronbach's alpha of the subscales (family stigmatization, social stigmatization and effect on performance) was excellent.

of relationship between an attribute and a stereotype is called stigma. Female athletes face more stigmatization than male athletes. The initial four segments of their definition marking, stereotyping, subjective partition, and passionate responses included.

The female student athletes have to manage gender in three folds, they had to manage 
gender, athletic identity and female athletic identity. Female athletes are always compared on the basis of their gender. They are always considered less powerful and inferior than male athletes. Female contestants had to face more struggle than male contestants found by the Seifriz et al. (2015) in addition to the contention. The female contestants were observed to face more conflict/controversy in regarding taking interest in manly games for example football, hockey, soccer, baseball and basketball. Female athletes also face harassment problems from their coach and male colleagues. This tool can be used as a screening tool to investigate other factors affecting the perceived stigmatization. For importance of psychology in sports, we can also organise awareness seminars and campaigns.

\section{Conclusions}

The current study aimed to develop an indigenous perceived stigmatization in sports scale for female athletes (PSSSFA). On the basis of scree plot and Eigen values, three factors were extracted: Family Stigmatization Social Stigmatization and Effect on Performance. The findings of the study tend to investigate factors affecting the perceived stigmatization associated with female athletes.

\section{Limitations and Suggestions}

The generalizability was limited because the sample included only females. The selfreported measures were used for collection of data so that's why the responses may be affected by individual differences (individual perception and interpretation). It may not be generalized on the athletes of different countries and cities because the sample of the study was taken only from Lahore.

It is advised to conduct more researches on perceived stigmatization that the female athletes face on daily basis in Pakistan. It is proposed to conduct lecture and seminar for common people for acceptance and to create awareness about problems of female athletes.

\section{Implications}

This study enhances understanding in the area of perceived stigmatization, motivational climate and sport perfectionism especially as this was only study investigated these variables jointly. Further validation studies can be conducted on this research which would strengthen its reliability. Results would help to investigate other factors affecting the perceived stigmatization, motivational climate and sport perfectionism. It is important to organize awareness campaigns and seminars for importance of psychology in sports.

And to enhance its reliability, we can also conduct further validation studies. We can also interrogate the other factors affecting perceived stigmatization using these results.

\section{Conflict of Interest}

There is no conflict of interest declared by authors.

\section{Source of Funding}

The authors declared no source of funding.

\section{References}

Alvarez, M. S., Balaguer, I., Castillo, I., \& Duda, J. L. (2012). The coach-created motivational climate, young athletes' well-being, and intentions to continue participation. Journal of Clinical Sport Psychology, 6(2), 166-179.

Ames, C. (2012). Achievement goals, motivational climate, and motivational processes. In G. Roberts (Ed.), Motivation in sport and exercise. Champaign, IL: Human Kinetics.

Brown, E. J., Heimberg, R. G., \& Leung, A. W. (2004). Relationship of perfectionism to affect, expectations, attributions and performance in the classroom. Journal of Social and Clinical Psychology, 18(1), 98-120. 
Cattell, R. B. (1966). The screen test for the number of factors. Multivariate Behavioral Research, 1, 245-276. http://dx.doi.org/10.1207/s15327906 mbr0102_10

Crocker, J., Major, B., \& Steele, C. (2008). Social stigma: the psychology of marked relationships. The handbook of social psychology, 2, 504-553.

Duda, J. L., \& Balaguer, I. (2007). CoachCreated Motivational Climate. In S. Jowette \& D. Lavallee (Eds.), Social Psychology in Sport (pp. 117-130). HumanKinetics. https://doi.org/10.50 40/9781492595878.ch-009.

Frost, R. O., \& Marten, P. A. (2011). Perfectionism and evaluative threat. Cognitive Therapy and Research, 14(6), 559-572.

Frost, R. O., Marten, P., Lahart, C., \& Rosenblate, R. (2011). The dimensions of perfectionism. Cognitive therapy and research, 14(5), 449-468.

Harrell, E. E. (2000). Regression Modelling Strategies with Applications to Linear Models, Logistic Regression and Survival Analysis. New York: Springer.

Hutcheson, G., \& Sofroniou, N. (1999). The Multivariate Social Scientist: Introductory Statistics Using Generalized Linear Models. Sage Publication, Thousand Oaks, CA.

Jones, E. E. (2002). Social stigma: The psychology of marked relationships. WH Freeman.

Jowett, S., \& Poczwardowski, A. (2007). Understanding the Coach-Athlete Relationship. In S. Jowette \& D. Lavallee (Eds.), Social Psychology in Sport (pp. 3-14). Human Kinetics.

Link, B. G., \& Phelan, J. C. (2001). Conceptualizing stigma. Annual review of Sociology, 27(1), 363-385.
Link, B. G., Yang, L. H., \& Collins, P. Y. (2014). Measuring mental illness stigma. Schizophrenia bulletin, 30(3), 511-541.

Mageau, G. A., \& Vallerand, R. J. (2003). The coach-athlete relationship: A motivational model. Journal of sports science, 21(11), 883-904.

Mallinson, S. H., Hall, H. K., \& Gotwals, J. K. (2017). The $2 \times 2$ model of perfectionism and school- and community- based sport participation. Psychology in the Schools, 51(9), 972-985.

Seifriz, J., Duda, J. L., \& Chi, L. (2015). The relationship of perceived motivational climate to achievementrelated affect and cognitions in basketball. Journal of Sport \& Exercise Psychology, 14, 375-391.

Slade, P. D., \& Owens, R. G. (2009). A dual process model of perfectionism based on reinforcement theory. Behavior modification, 22(3), 372-390.

Smith, R. E., Smoll, F. L., \& Barnett, N. P. (1995). Reduction of children's sport performance anxiety through social support and stress-reduction training for coaches. Journal of applied developmental psychology, 16(1), 125-142.

Stoeber, J., \& Otto, K. (2006). Positive conceptions of perfectionism: Approaches, evidence, challenges. Personality and social psychology review, 10(4), 295-319.

Tabachnick, B. G., \& Fidell, L. S. (2007). Using Multivariate Statistics (5th ed.). New York: Allyn and Bacon.

Vazou, S., Ntoumanis, N., \& Duda, J. L. (2005). Peer motivational climate in youth sport: A qualitative inquiry. Psychology of sport and exercise, 6(5), 497-516. 